\title{
Cognitive Control Strategies and Adaptive Performance in a Complex Work Task
}

\author{
Cornelia Niessen ${ }^{1}$ and Jonas W. B. Lang ${ }^{23}$ \\ ${ }^{1}$ Department of Psychology, Work and Organizational Unit, Friedrich-Alexander University of \\ Erlangen-Nürnberg \\ ${ }^{2}$ Department of Human Resource Management and Organizational Psychology, Ghent University \\ ${ }^{3}$ Business School, University of Exeter
}

(C) 2020, American Psychological Association. This paper is not the copy of record and may not exactly replicate the final, authoritative version of the article. Please do not copy or cite without authors' permission. The final article will be available, upon publication, via its DOI: 10.1037/apl0000830

\section{Author Note}

Cornelia Niessen https://orcid.org/0000-0003-1994-3677

Jonas W. B. Lang https://orcid.org/0000-0003-1115-3443

This research was funded by the German Research Council (Deutsche Forschungsgemeinschaft, DFG, NI 1066/3-1). We thank Kryra Göbel and Tanja Kurzendörfer for supporting data collection of Study 2, and Wolfgang Grund for programming the experimental task.

Correspondence concerning this article should be addressed to Cornelia Niessen, Department of Psychology, Work and Organizational Unit, Friedrich-Alexander University of Erlangen-Nürnberg, Nägelsbachstr. 49c, 91052 Erlangen, Germany. Email:

cornelia.niessen@fau.de 


\begin{abstract}
Adapting to task changes in work settings frequently calls not only for shifting one's thoughts and behaviors to the new demands, but also for dealing with outdated knowledge and skills. This article focuses on the role of control strategies in task adaptation, and reports two experimental studies using an air traffic control simulation task. In both studies $(N=66$ and 105 with $k=1,320$ and 1,680 observations, respectively), all participants first learned and performed an initial version of the task, then received instruction about control strategies, performed an altered version of the task with new execution rules, and finally worked on a memory test. Participants were instructed to either deliberately forget the old rules, remember the old rules, or simply learn the new task (Study 2 only). Results from discontinuous growth curve modeling revealed that the directed forgetting in both studies and the control group in Study 2 showed higher performance in the simulation after the change relative to their performance before the change (transition adaptation). There were no relearning differences between the groups suggesting that these differences persisted throughout the task. However, the memory test at the end of the study revealed that the directed forgetting groups and the learning control group remembered less outdated task execution rules in the memory test after the simulation than the remembering group. The findings suggest that different types of cognitive strategies have costs and benefits. Conceptual and practical implications of these findings are discussed.
\end{abstract}

Keywords: adaptive performance, directed forgetting, intentional forgetting, self-control, cognitive control 


\section{Cognitive Control Strategies and Adaptive Performance in a Complex Work Task}

Human adaptability is a crucial skill in today's organizations because employees are increasingly confronted with changes in their work tasks (Baard, Rench, \& Kozlowski, 2014; Chan, 2000; Griffin, Neal, \& Parker, 2007; Jundt, Shoss, \& Huang, 2014). After a change in work demands, outdated knowledge and work procedures are typically not suddenly and automatically forgotten, and may be retained and preserved as an alternative to action, parallel to the new procedures (e.g., Labianca, Gray, \& Brass, 2000). Retaining old procedures may lead to negative consequences or even threaten safety in high-risk organisations such as air traffic management and railway networks. However, retaining outdated information may also provide relevant knowledge and experiences that may become relevant again at some point depending on the nature of the task environment.

In the present study, we focus on cognitive strategies in dealing with work procedures that are not relevant anymore after a change. We are specifically interested in the impact of cognitive strategies on adaptation to new task demands, and employees' ability to remember old strategies. Over the past two decades, theories (e.g., Dawis, 2005; Ployhart \& Bliese, 2006) and empirical studies on adaptation have studied a variety of predictors of employees' ability to deal with new task demands (e.g., Allworth \& Hesketh, 1999; Baard, et al., 2014; Bell \& Kozlowski, 2008; Chan, 2000; Jundt, et al., 2014; Lang \& Bliese, 2009; Ployhart \& Bliese, 2006; Pulakos, Donovan, \& Plamondon, 2000). However, we are not aware of any research studying how employees deal with outdated information. We aim to address this gap by asking if and how cognitive control strategies, such as retaining outdated task procedure in memory, intentionally forgetting these procedures, and doing nothing by will impact task adaptation in a frequently studied complex aviation task (e.g., Ackerman, Kanfer, \& Goff, 1995; Kanfer \& Ackerman, 
1989, Yeo \& Neal, 2004). Thereby, we contribute to the literature in at least two ways.

First, we seek to expand I-O psychologists understanding of the real-world implications of cognitive control strategies. Organizational change and management research frequently discuss cognitive strategies like unlearning, replacing, or ignoring (de Holan \& Phillips, 2004; Hislop, Bosley, Coombs, \& Holland, 2014; Kluge \& Gronau, 2018). To our knowledge, cognitive strategies have rarely been examined in real-world work tasks like air-traffic controlling. One cognitive strategy that has been frequently studied in the cognitive literature is intentional forgetting. Intentional forgetting is typically described as a motivated attempt to limit access to task-irrelevant knowledge in memory (Anderson \& Hanslmayr, 2014; Sahakyan, Delaney, Foster, \& Abushanab, 2013), and contrasts with intentional remembering as an alternative strategy. Cognitive psychology research suggests that individuals are able to intentionally forget episodic and declarative knowledge such as words and action phrases, and conversely, can also be instructed to intentionally keep old knowledge in memory as an alternative strategy (Anderson \& Green, 2001; Basden \& Basden, 1998; Bjork \& Bjork, 2003; Chen et al., 2012; Depue, Banich, \& Curran, 2006; Dreisbach \& Bäuml, 2014; Gagnepain, Henson, \& Anderson, 2014; Golding \& MacLeod, 1998; Joslyn \& Oakes, 2005; Noreen \& MacLeod, 2013, 2014; Sahakyan \& Foster, 2009; Sahakyan \& Delaney, 2005; Stephens, Braid, \& Hertel, 2013). However, it is currently not clear whether using such cognitive strategies has real world implications and is different from unspecific instructions (i.e., learn the new task).

Second, by investigating cognitive control strategies we explicitly examine the mechanisms involved in the adaptation process, which is an underdeveloped field of research (Baard et al., 2014; Jundt et al., 2014), using experimental manipulations of cognitive strategy instructions. To adequately model the adaptation trajectories and the potential impact of 
cognitive strategies on these trajectories, we rely on discontinuous growth modeling (Bliese, Adler, \& Flynn, 2017; Bliese \& Lang, 2016; Bliese \& Ployhart, 2002; Singer \& Willett, 2003), which allows for analysing and predicting two different types of adaptation: the immediate decrease in performance directly after a change (transition adaptation), and recovering and relearning later on (reacquisition adaptation; Bliese, Chan, \& Ployhart, 2007; Bliese, McGurk, Thomas, Balkin, \& Wesensten, 2007; Lang \& Bliese, 2009).

\section{Task Adaptation}

Adaptation or adaptability is a broad concept and the research literature on the topic includes a variety of different approaches. For example, research on adaptation includes studies measuring generic adaptive capabilities and traits (Ployhart \& Bliese, 2006; Pulakos et al., 2000; Pulakos et al., 2002), research that builds on the cognitive training literature and focuses on cognitive processes and expertise development (e.g., Holyoak, 1991), and work that directly extends the skill acquisition literature to include reactions to task-changes (e.g., Kanfer \& Ackerman, 1989; for an overview see Baard, et al. 2014; Jundt et al., 2014). The two later approaches are most closely aligned with common definitions of adaptation as an "individual's response to new demands or ill defined problems created by uncertainty, complexity, mergers, and any rapid change in the work situation" (Chan, 2014) or "cognitive, affective, motivational, and behavioral modifications made in response to the demands of a new or changing environment, or situational demands" (p. 50, Baard et al., 2014). A frequent critique of research on adaptation is that it remains often unclear which specific changed task components required adaptation and which processes underly adaptive performance (Baard et al., 2014). We aimed to fill this gap by combining research strategies from the cognitive training and skill acquisition literatures. Building on the cognitive training literature, we operationalized task change as a 
change of stimulus-response associations and adaptation as a function of cognitive control processes and experimentally manipulated these characteristics across time and between groups, respectively. Building on the skill acquisition literature, we extracted adaptive change from change trajectories by modeling skill acquisition in combination with adaptive change after a task-change (e.g., Ackerman \& Cianciolo, 2002; LePine, Colquitt, \& Erez, 2000). This approach is also known as the the task-change paradigm (Betsch, et al., 2004; Bröder \& Schiffer, 2006; Lang \& Bliese, 2009; LePine et al., 2000; Schunn \& Reder, 2001). The task-change approach specifically compares task performance prior and after an expected (Ackerman \& Cianciolo, 2002; Bröder \& Schiffer, 2006) or unexpected (e.g., Lang \& Bliese, 2009; LePine et al., 2000) task change. In the pre-change phase, individuals are required to acquire task-related knowledge and develop a new skill by practising a task. In the post-change phase, individuals then have to accomplish the same task but in a different manner, which requires relearning. In the present experiments, we investigated an expected change as we studied the implementation of new task procedures over time rather than the ability to even notice a change at all, which would play an additional role in an unexpected change.

Research on adaptation has typically distinguished two compoments of adaptation in the post-change phase (Jundt et al., 2014; Lang \& Bliese, 2009): (1) transition adaptation, and (2) reacquisition adaptation. Transition adaptation refers to deliberately reorganizing task-related knowledge structures and skills (French \& Sternberg, 1989) while outdated and routinized strategies are still active, and might interfere with the new task procedure (Niessen \& Jimmieson, 2016). Consequently, transition adaptation requires attention. With more practice, individuals engage in reacquisition adaptation and task performance improves, becoming faster and more accurate. Reacquisition adaptation involves learning while avoiding intrusions of the skills 
learned prior to the change, and als captures how lasting transition adaptation effects are across the course of a change trajectory and also contributes to a deeper understanding of transition adaptation effects. In the present study, we therefore investigated how both components of the adaptation process, transition adaptation and reacquisition adaptation, are shaped by cognitive control strategies.

\section{Cognitive Control Strategies}

At work, employees often need to decide how they should deal with knowledge and skills that have become outdated. Should they retain the old knowledge and skills because they anticipate that the outdated knowledge and skills may become relevant again (Labianca, et al., 2000) or should they try to eliminate the outdated information from their behavioral repertoire (de Holan \& Phillips, 2004; Hislop et al., 2014; Kluge \& Gronau, 2018)? Forgetting might be a potentially effective strategy for dealing with task-irrelevant knowledge and task procedures, which are still active in memory and might interfere with the accomplishment of the new tasks after change. Forgetting can be an unconscious, automated process such as memory decay over time, which is often experienced negatively as error and weakness. However, forgetting can also be intentional and conscious. As the motivated attempt to limit retrieval of unwanted or irrelevant knowledge in memory (Anderson \& Hanslmayr, 2014), intentional or directed forgetting has been described as an adaptive process. In everyday situations, intentional forgetting updates memory, supports affect regulation, helps people to preserve their self-image, to forgive others, and to stay concentrated when distracting thoughts would otherwise compete for their attention (e.g., Nørby, 2015).

There is considerable evidence that individuals are capable to deliberately regulate forgetting vs. remembering when they are instructed to do so. One prominent and widely studied 
paradigm for investigating directed forgetting vs. remembering is the list method (Bjork, 1972). In this paradigm, participants are asked to learn two lists of items like words (e.g., Basden \& Basden, 1998; Bjork \& Bjork, 2003; Golding \& MacLeod, 1998; Sahakyan \& Delaney, 2005). Before learning the second list, participants are either instructed to remember (the remember condition) or to forget the first list (the forget condition). At the end, memory of both lists is tested. Results from this paradigm have typically shown that the instruction to forget has both benefits and costs. The benefits of directed forgetting are better memory of items from List 2, while the costs are impaired memory of the old information (i.e. items from List 1; for an overview see Anderson, 2005; Anderson \& Hanslmayr, 2014; Golding \& MacLeod, 1998; Lehman \& Malmberg, 2009).

Studies using the list method have mainly used episodic and declarative knowledge such as lists of words (e.g., Anderson \& Green, 2001; Bjork, 1972). As one exception, Dreisbach and Bäuml (2014) found that the instruction to forget limited the automatic retrieval of simple habits. The costs and benefits of directed forgetting vs. directed remembering in the list method have theoretically been explained by several mechanisms. The mental context change hypothesis (Sahakyan \& Delaney, 2005; Sahakyan \& Kelley, 2002) posits that two separate processes account for the costs (context change) and benefits (strategy change) of directed forgetting. First, the forget cue triggers that individuals represent the first list and the second list as separate events or (temporal) contexts (i.e. context change), which has two consequences: (a) retrieval of List 1 items in the subsequent memory test (costs) is impaired, and (b) proactive interference (i.e., old information reduces recall of new information) is reduced. Second, the benefits of forgetting are explained by strategy changes (Sahakyan \& Delaney, 2003): Individuals might learn List 2 items in more detail (i.e., using a different encoding strategy) compared to the 
remember group (Sahakyan \& Delaney, 2003). This theory is supported by several studies (e.g., Bäuml, Hanslmayr, Pastötter, \& Klimesch, 2008; Lehman \& Malmberg, 2009; Sahakyan \& Delaney, 2003; Shapiro et al., 2006). Anderson (2005) provided evidence for a general inhibitory mechanism which is responsible for the context change and the impaired retrieval of single items by lowering the activation level for a given response. Behavioral neuroimaging provides evidence in support of inhibitory control processes that enable individuals to stop response tendencies (see Anderson \& Hanslmayr, 2014; Anderson et al., 2004; Depue, Orr, Smolker, Naaz, \& Banich, 2015).

From the perspective of applied psychology, it is important to know, whether intentional instructions to either remember or forget actually make a difference in the context of a real-world task. A second research question is to what degree specific control instructions to either remember or forget affect employees in complex cognitive relative to an unspecific "learn the new task" instruction.

\section{Hypotheses}

Based on the directed forgetting vs. remembering paradigm and the applied questions discussed in the previous section, we conducted two experiments using an air traffic control simulation adapted from Kanfer and Ackerman (1989). This air-traffic simulation is an environment that realistically simulates the decision-demands of real air-traffic controlling of incoming planes and has thus widely been adopted as one of the most realistic scenarios for studying complex task performance (e.g., Ackerman et al., 1995; Yeo \& Neal, 2004). In the first phase of experiments (pre-change phase), individuals had to learn a pre-described set of rules for landing aircraft and were instructed to apply these rules in repeated trials during the air traffic control simulation. Then, participants were either instructed to remember these rules (remember 
condition) or to forget these rules (forget condition) before they learned a second set of new rules. In experiment 2, we included a third condition asking participants to simply "learn the new task" as a control condition. In the second phase of the experiments, participants needed to perform the new ATC task. After the end of this second phase of the experiments (post-change phase), individuals were tested on their recognition of all rules from both rule sets. Furthermore, participants were asked whether they intentionally tried to remember the old rules.

Building on the theory and research discussed in the previous two sections, we developed two sets of hypotheses. First, we hypothesized that the recognition task at the very end of the experiments should lead to differences between the experimental groups. We specifically expected that participants in the intentional forgetting condition would remember less rules than participants in the intentional remembering condition (costs of intentional forgetting). Second, we assumed that participants in the forgetting condition would have advantages in learning and in applying the new rules, and that these advantages would translate to advantages in transition adaptation and in reacquisition adaptation.

Hypothesis 1: Recognition of the first rule set is significantly lower in the forget condition than in the remember condition (Both Experiments), and in the "learn the new task" condition. (Experiment 2 only)

Hypothesis 2: Transition adaptation is better in the forget condition than in the remember condition (Both Experiments), and the in the "learn the new task" condition (Experiment 2 only). Hypothesis 3: Reacquisition adaptation is better in the forget condition than in the remember condition (Both Experiments), and the in the "learn the new task" condition (Experiment 2 only).

\section{Experiment 1}

\section{Methods}


Participants. Sixty-six individuals from the general population participated in the experiment for $€ 35$ ( $45 \%$ female, mean age $=39$ years, $S D=11.93$ years; age range 21-65 years; 33 participants in the forget condition, 33 in the remember condition, randomly assigned). T-tests showed that age levels, $t(64)=0.94, p=.352$, were comparable across experimental conditions. Participants all worked in regular jobs.

Experimental Task. The participants' main task was to land planes safely and efficiently according to predefined rules in a computer-aided air traffic control (ATC) task (for a detailed description see the Appendix) adapted from Kanfer and Ackerman (1989, see Figure 1). The planes in this simulation were designated with simple call signs (the letter A, B, K or M and a number; e.g., B 613), and crashed 4 to 6 minutes after appearing on the display if it did not land on the appropriate runway (in real time). The experiment included 20 trials, 10 trials in the prechange phase $(1-10)$ and 10 trials in the post-change phase $(11-20)$. In each trial, participants were asked to land 24 planes ( 480 planes in total). We assumed that after landing 240 planes according to specific rules in the pre-change phase, participants should have acquired a modest level of practice with these rules, sufficient to examine relearning. For manipulating the task change, we used two sets of four specific rules (see Table 1): Participants were requested to land planes according to one rule set in the pre-change phase (trials 1-10) and a different rule set in the post-change phase (11-20).

Procedure and Manipulation. The main experiment started with learning the first set of four specific rules for landing planes, which was followed by a recognition test for each rule (presented for 30 seconds), one after the other. Only if there were no recognition errors did the first simulation trial start; otherwise, participants had to relearn the four rules and were tested a second time with a recognition test. Participants were then instructed to land 24 planes in each of 
10 trials according to these four rules. Participants gained or lost points for performing different ATC tasks, which was displayed in the top right-hand corner in all conditions.

After the first 10 trials (trials 1-10, 240 planes in total), we manipulated task change and forgetting and remembering. We implemented task change by altering the two rule sets consisting of four specific rules each. The rule sets were varied systematically. Forgetting and remembering were manipulated by instructions. We used the standard instruction for directed forgetting (list method; forget group: "Please forget the rules you have learned and applied before and learn the new rules"; remember group: "Please remember the previously learned rules and learn the new rules"). Then, the second phase of the experiment (post-change phase) started with learning the second set of four rules. Again, memory of these rules was tested using a recognition test. If all answers were correct, the participants were then instructed to land planes in 10 subsequent trials (trials 11-20, 240 planes in total) according to these new rules. After landing 240 planes according the new rules an unexpected recognition test of all eight rules (from both rule sets) plus eight distractor rules was then used to assess forgetting and remembering of the rules (see Table 1). All rules were displayed one at a time in the middle of the screen in random order. Participants responded to each rule as fast and accurate as possible by pressing the yes button if the rule was part of one of the two rule sets, and the no button if the rule was new (a distractor).

Research Design. The experimental design included a forget condition and a remember condition (between-persons), as well as 10 trials of task performance prior to the rule change and 10 trials of task performance after the rule change (within-person; see Figure 2).

Dependent Measures. We assessed three dependent variables: (1) Frequencies of correct answers on the last recognition test assessing memory of the old rules from the pre-change 
phase; (2) rule violations for each trial indicating proactive interference caused by the first rule set in the post-change phase; (3) performance scores (points) for each trial. Points were earned by landing planes ( +50 points) and lost through rule violations (-10 points) or plane crashes (100 points).

Manipulation Check and Task Motivation. At the end of the simulation, we asked the participants to what degree they tried to remember the old rules as a manipulation check using a scale from 1 (Strongly Disagree) to 5 (Strongly Agree). We also assessed task motivation with four items ("looking forward to playing more ATC", "interested in playing ATC", "playing the ATC is fun", "playing ATC is involving") using the same scale (Cronbach's $\alpha=.82$ ).

\section{Results}

Descriptive Statistics and Manipulation Checks. Descriptive statistics and correlations for the study variables are presented in Tables 2 and 3. Participants ' motivation to play the ATC simulation did not differ significantly between the condition; $t(64)=1.16, p=.249)$. As shown in Table 3, the manipulation check was significant and participants in the remember condition reported more that they tried to remember the old rules more than in the forget condition.

Recognition Test. T-tests showed that the hit rate for the first (old) rule set was lower among participants in the forget condition compared to the remember condition (see Table 3). Hypothesis 1 was thus supported ${ }^{1}$.

Task Adaptation. We used discontinuous growth modeling to analyze the data (Singer \& Willett, 2003). All models were fitted using the lme4 package (Bates, Maechler, Bolker, \& Walker, 2015) included in R (R Core Development Team, 2018) and were two-level models, with trials at Level 1 (10 trials before and 10 trials after the change) nested within individuals at Level 2. We adapted the coding approach by Singer and Willett (2003) that has been utilized to 
understand task adaptation in earlier research (e.g., Howe, 2019; Lang \& Bliese, 2009; Niessen \& Jimmieson, 2016). This approach uses time variables for baseline performance - skill acquisition in the pre-change phase, and transition adaptation and reacquisition adaptation in the post-change phase - and allows researchers to analyze the drop in points directly after the change (transition acquisition) and the rate of post-change relearning (reacquisition adaptation). Specifically, we used the following Level-1 model: $Y_{\mathrm{ti}}=\pi_{0 \mathrm{i}}+\pi_{1 \mathrm{i}} S A_{\mathrm{t}}+\pi_{2 \mathrm{i}} S A_{\mathrm{t}}{ }^{2}+\pi_{3 \mathrm{i}} T A_{\mathrm{t}}+\pi_{4 \mathrm{i}} R A_{\mathrm{t}}+$ $\pi_{5 \mathrm{i}} R A_{\mathrm{t}}^{2}+e_{\mathrm{ti}}\left(\right.$ with $\left.e_{\mathrm{ti}} \sim N\left[0, \sigma^{2}\right]\right)$. Table 4 shows the coding of the time variables on the basis of this absolute coding (Bliese, Kautz, \& Lang, in press; Bliese \& Lang, 2016) ${ }^{2}$. First, SA and SA ${ }^{2}$ represent the linear and quadratic learning slopes prior to the change. Second, transition adaptation is captured by a dummy-coded time variable (TA) contrasting the levels of the DV immediately before and after the change. Third, reacquisition adaptation is coded using a linear and a quadratic change variable $\left(\mathrm{RA}, \mathrm{RA}^{2}\right)$ that captures the learning rate after the change relative to zero and directly indicates whether substantial learning took place after the change. Finally, baseline task performance is reflected by the intercept and captures the level of performance at the start of the study.

Table 5 shows the results of the discontinuous growth modeling analyses. In the present study, we build on recommendations for experimental work with mixed-effects models that emphasizes the need to test a-priori specified models while balancing complexity and parsimony (Bates et al., 2015; Bliese, Kautz, \& Lang, in press; Matuschek et al., 2017) in testing the effect of the experimental manipulation at Level-2. We specifically included the dummy variable CONDITION contrasting the forgetting group (coded 1) with the remembering group (coded 0) for elements of the model that we a-priori predicted based on our hypotheses. We began with a model that included CONDITION as a predictor of the average level at the start of the study, $\pi_{0 \mathrm{i}}$ 
$=\gamma_{00}+\gamma_{01} C_{\text {CONDITION }}+r_{0 \mathrm{i}} ; \pi_{1 \mathrm{i}}=\gamma_{10} ; \pi_{2 \mathrm{i}}=\gamma_{20}$, and the transition, $\pi_{3 \mathrm{i}}=\gamma_{30}+\gamma_{31}$ CONDITION $_{\mathrm{i}}$; $\pi_{4 \mathrm{i}}=\gamma_{40} ; \pi_{5 \mathrm{i}}=\gamma_{50}\left[\right.$ with $\left.r_{0 \mathrm{i}} \sim N(0, \tau)\right]$. We next fitted a model that included CONDITION as a predictor of the reacquisition terms $\left(\pi_{4 \mathrm{i}}=\gamma_{40}+\gamma_{41}\right.$ CONDITION $_{\mathrm{i}}$ and $\pi_{5 \mathrm{i}}=\gamma_{50}+\gamma_{51}$ CONDITION $\left._{\mathrm{i}}\right)$ but not as a predictor of the transition effect to examine the reacquisition effect in isolation. We finally also fitted a model that included CONDITION as a predictor of both the reacquisition effect and the transition effects. As indicated by Table 5, results revealed that all level-1 change terms were significant. Most importantly, the linear and quadratic change terms suggested that there was a learning curve prior to the change, a marked decline in performance after the change, and a recovery in the amount of rule violations after the change for both dependent variables. The analyses also revealed a significant effect of the condition on transition adaptation, supporting Hypothesis 2. The model with condition as a predictor of reacquisition instead of transition revealed a significant linear reacquisition effect, supporting Hypothesis 3. However, when both reacquisition and transition adaptation were allowed to be predicted by condition in the final model, only transition effect was significant suggesting that participants did not differ in their reacquisition adaptation after controlling for transition adaptation differences. These findings suggest that the differences between the two conditions were relatively long lasting. Figure 3 plots the overall change pattern and the exact nature of the differences between the two groups after the introduction of the change.

\section{Experiment 2: Replication and Control Group}

In Experiment 2, we aimed to replicate the results of the first experiment. In addition, we included a control group to study how participants act typically when they do not get instructions related to forgetting or remembering.

\section{Method}


The participants were 105 university undergraduates (in return for course credit or alternatively $€ 15 ; n=30$ in the forget condition, $n=43$ in the remember condition, $n=32$ in the control condition). Seventy-seven participants were female, 27 male, and one person who checked "divers". Mean age was $22.82(S D=5.29)$. The experimental task for Experiment 2 was the same as the task used in Experiment 1 with one exception. Participants were required to run a sequence of 16 trials (in each trial 24 planes to land), and not 20 trials as in the first experiment: eight trials in the prechange phase $(1-8)$ and eight trials in the postchange phase $(9-16)$. The number of trials was reduced as Experiment 1 showed that participants acquired a modest level of practice with the rules after the seventh or eighth trial (see also Niessen \& Jimmieson, 2016). The procedure for Experiment 2 was the same as the procedure for Experiment 1. However, after the first eight trials, we added the control instruction ("Please learn the new rules") to the forget instruction and remember instruction.

We assessed the same dependent variables as in Experiment 1. In addition, after the fifth trial, task effort was assessed with three items of the scale of Earley, Wojnaroski, and Prest (1987) ranging from 1 (Strongly Disagree) to 5 (Strongly Agree). Items asked participants if they put a lot of effort into their work, if they worked very hard on their tasks, and if they fully concentrated on their work tasks. Cronbach's alpha was .82 (post-change phase).

\section{Results}

Descriptive Statistics and Manipulation Checks. Table 6 shows descriptive statistics and correlations for study variables, and Table 3 also includes group comparisons for Study 2. There were no significant differences between the conditions with respect to task motivation, $F_{(2 \text {, }}$ ${ }_{103)}=1.75, p=.18$, and task effort, $F_{(2,103)}=0.61, p=.55$. Again, the manipulation check revealed that participants in the remember condition reported that they tried to remember the old 
rules more than participants in the forget condition (see Table 3). The remember condition also reported more remembering of old rules than the learn the new rules condition. The forget and the learn the new rules condition did not statistically differ.

Recognition Test. T-tests revealed that the hit rate for the first (old) rule set was lower among participants in the forget condition compared to the remember condition, but this difference was not significant (see Table 3). However, we found a significantly lower recognition rate in the control condition compared to the remember condition. The hit rate for the first (old) rule set did not differ between the forget condition and the control instruction. Hypothesis 1 was thus only partly supported.

Task Adaptation. We conducted similar discontinuous mixed-effects modeling analyses like in Experiment 1, but used two dummy variables. The first dummy variable CONDTION1 contrasted the control group (coded 1) with the remembering group (coded 0$)$. The second dummy code CONDITION2 contrasted the directed forgetting group (coded 1) with remembering (coded 0) like in Experiment 1. Table 7 provides the results for both dependent variables - rule violations and points - and revealed that the forget group and the control group differed from the remembering group in transition adaptation, providing support for Hypotheses 2. We found no support for differences between the groups on reacquisition adaptation providing no support for Hypothesis 3. Figure 4 again provides box plots over time and predicted values for the discontinuous mixed-effects models.

\section{Discussion}

This report examined how cognitive strategies affect how participants from the general working population (Experiment 1) and undergraduates (Experiment 2) deal with old task routines that have become obsolete after a change, and adapt to new task demands. Three key 
findings emerged. First, we found evidence that instructing participants to remember the old rules impaired their task performance in the new task relative to both a directed instruction to forget (Experiment 1 and 2), and a non-specific instruction to learn the new task. These changes occurred directly after the change (transition adaptation), and persisted throughout the second phase of the experiments, in which participants worked on the altered task with new rules (no reacquisition adaptation effect). Second, we found some evidence that the instruction to remember the old task had benefits in recalling the old rules after at the end of the study. The remember groups partly outperformed the groups of participants instructed to forget the old rules, and the group of participants instructed to learn the new task in Experiment 2. Third, we found no significant differences between participants instructed to forget the old rules and participants instructed to learn the new task in Experiment 2.

\section{Theoretical and Practical Implications}

Our study has several implications. A theoretical implication of our findings is that individuals are able to intentionally limit access to well-learned stimulus response associations (i.e., procedural knowledge) and reduce the strength of these associations in complex work tasks. This finding is in line with previous behavioral and neuropsychological studies (e.g., Anderson \& Hanslmayr, 2014) but the experiments we reported are the first studies of which we are aware that show effects of this type in the context of a complex work task. A second implication of our study that is both theoretically and practically relevant is that directed forgetting instructions can have similar effects as more general learn the new task instructions. This finding is somewhat in line with findings in the extant literature suggesting that explicit ("forget List 1") and implicit instructions to forget ("remember only List 2") can have similar effects (Foster \& Sahakyan, 2011; Lehmann \& Malmberg, 2009). A plausible explanation in the context of the current study 
is that broad instructions to learn the new task provide a sufficient cue for participants to use memory suppression strategies. In line with this idea, there were no differences between the two groups in the manipulation check in Experiment 2.

A practical implication of our studies is that using cognitive control strategies has both costs and benefits in organizational settings. Explicit instructions to forget or learn the new rules seem to improve task performance but also reduces recognition and thus likely also skill in case an organization would need to fall back on old task routines. Our studies found no clear benefits of directed forgetting instruction and thus the current study suggests that instructing employees to forget has no scientific support on the basis of the current set of studies. This being noted, it is possible that directed forgetting instructions may have advantages in other task settings. ATC is a task setting that naturally makes participants somewhat alert to rapid changes and different scenarios which is why participants may have a natural tendency to use directed forgetting even when they are not explicitly instructed to do so. It is not difficult to imagine scenarios in which participants may feel inclined to by default remember old rules and task routines. Overall, our findings suggest that organizations should be alert about control instructions they provide during training (e.g., "always remember this rule"). The paradigm we used in the current research could allow researchers to also study the use of control strategies in other types of task environments by contrasting directed forgetting, directed remembering, and unspecific instructions to learn in future research. Furthermore, our findings add also some value for the training literature in that they potentially have implications for adaptive forms of training transfer (Aguinis \& Kraiger, 2009).

\section{Strengths and Limitations}

Strengths of the experiments include the fact that we manipulated experimentally 
manipulated cognitive control strategies and thus the effects allow for causal interpretations. We also assessed task adaptation at multiple measurement occasions, enabling us to model growth curves and different components of adaptive task performance and partly (Experiment 1) relied on participants from the general working population with a broad age range. One limitation of the present research is the fact that the we investigated adaptation during a limited time period (2.5 hours). Accordingly, our findings may not hold for adaptation in more complex realworld environments with multiple task-changes across extended periods of time. However, the participants in both experiments learned the task until the learning curve showed clear evidence of flattening out suggesting at least some level of asymptotic task mastery. Moreover, remembering or forgetting effects could also be stronger in more realistic settings. For example, Anderson and Hanslmayr (2014) suggested that individuals in everyday life are more motivated to forget unwanted thoughts because they believe that cognitive control strategies have a positive impact. A second limitation of the present studies is that we focused on a specific conceptualization of change (change in rules), which limits the generalizability of our results. Finally, one could argue that the lower recognition rates in the forget group can be due to the intentional withholding of to-be-forgotten items in the final recognition test. However, it seems unlikely that the "good participant hypothesis" account for the forgetting cost because of the following reasons: First, the test was unexpected, second, the test included eight distractor rules, third, previous research has shown that even a monetary incentive for the recall of to-beforgotten items did not increase the recall rates of these items (MacLeod, 1999), and fourth, the control group ("lean the new rules") revealed comparable results.

\section{Conclusion}

This report extends research on adaptive task performance in industrial and 
organizational psychology by building on research in cognitive psychology, and studied the role of control strategies in adaptive task performance in a complex ATC task. Our results suggest that cognitive control strategies can alter both the efficiency of adaptation and the recall of old knowledge, and thus suggest that organizations should carefully decide when they use control strategy instructions in training and in their daily organizational routine. 


\section{References}

Ackerman, P. L., \& Cianciolo, A. T. (2002). Ability and task constraint determinants of complex task performance. Journal of Experimental Psychology: Applied, 8(3), 194-208. doi:10.1037/1076-898x.8.3.194

Ackerman, P. L. (1988). Determinants of individual differences during skill acquisition: Cognitive abilities and information processing. Journal of Experimental Psychology: General, 117(3), 288-318. doi:10.1037/0096-3445.117.3.288

Ackerman, P. L., Kanfer, R., \& Goff, M. (1995). Cognitive and noncognitive determinants and consequences of complex skill acquisition. Journal of Experimental Psychology: Applied, 1(4), 270-304. doi:10.1037/1076-898x.1.4.270

Aguinis, H., \& Kraiger, K. (2009). Benefits of training and development for individuals and teams, organizations, and society. Annual Review of Psychology, 60(1), 451-474. doi:10.1146/annurev.psych.60.110707.163505

Allworth, E., \& Hesketh, B. (1999). Construct-oriented biodata: Capturing change-related and contextually relevant future performance. International Journal of Selection and Assessment, 7(2), 97-111. doi:10.1111/1468-2389.00110

Anderson, J. R. (1983). A spreading activation theory of memory. Journal of Verbal Learning and Verbal Behavior, 22(3), 261-295. doi:10.1016/s0022-5371(83)90201-3

Anderson, J. R. (1995). Cognitive psychology and its implications. New York: Freeman.

Anderson, M. C. (2005). The role of inhibitory control in forgetting unwanted memories: A consideration of three methods. In C. MacLeod, \& B. Uttl (Eds.), Dynamic cognitive processes (pp. 159-190). Springer Japan.

Anderson, M. C., \& Green, C. (2001). Suppressing unwanted memories by executive control. 
Nature, 410(6826), 366-369. doi:10.1038/35066572

Anderson, M. C., \& Hanslmayr, S. (2014). Neural mechanisms of motivated forgetting. Trends in Cognitive Sciences, 18(6), 279-292. doi:10.1016/j.tics.2014.03.002

Anderson, M. C., Ochsner, K. N., Kuhl, B., Cooper, J., Robertson, E., Gabrieli, S. W., ... Gabrieli, J. D. E. (2004). Neural systems underlying the suppression of unwanted memories. Science, 303(5655), 232-235. doi:10.1126/science.1089504

Baard, S. K., Rench, T. A., \& Kozlowski, S. W. J. (2014). Performance adaptation: A theoretical integration and review. Journal of Management, 40(1), 48-99. doi:10.1177/0149206313488210

Basden, B. H., \& Basden, D. R. (1998). Directed forgetting: A contrast of methods and interpretations. In J. M. Golding, \& C. M. MacLeod (Eds.), Intentional forgetting: Interdisciplinary approaches. (pp. 139-172). Mahwah, NJ US: Lawrence Erlbaum Associates Publishers.

Bates, D., Mächler, M., Bolker, B., \& Walker, S. (2014). Fitting linear mixed-effects models using lme4. arXiv preprint arXiv:1406.5823.

Bäuml, K.-H., Hanslmayr, S., Pastötter, B., \& Klimesch, W. (2008). Oscillatory correlates of intentional updating in episodic memory. NeuroImage, 41(2), 596-604. doi:10.1016/j.neuroimage.2008.02.053

Bell, B. S., \& Kozlowski, S. W. J. (2008). Active learning: Effects of core training design elements on self-regulatory processes, learning, and adaptability. Journal of Applied Psychology, 93(2), 296-316. doi:10.1037/0021-9010.93.2.296

Betsch, T., Brinkmann, B. J., Fiedler, K., \& Breining, K. (1999). When prior knowledge overrules new evidence: adaptive use of decision strategies and the role of behavioral 
rouines. Swiss Journal of Psychology, 58(3), 151-160. doi:10.1024//1421-0185.58.3.151

Betsch, T., Haberstroh, S., Molter, B., \& Glöckner, A. (2004). Oops, I did it again-relapse errors in routinized decision making. Organizational Behavior and Human Decision Processes, 93(1), 62-74. doi:10.1016/j.obhdp.2003.09.002

Bjork, E. L., \& Bjork, R. A. (2003). Intentional forgetting can increase, not decrease, residual influences of to-be-forgotten information. Journal of Experimental Psychology: Learning, Memory, and Cognition, 29(4), 524-531. doi:10.1037/0278-7393.29.4.524

Bjork, E. L., \& Bjork, R. A. (1996). Continuing influences of to-be-forgotten information. Consciousness and Cognition, 5(1-2), 176-196. doi:10.1006/ccog.1996.0011

Bjork, E. L., Bjork, R. A., \& Anderson, M. C. (1998). Varieties of goal-directed forgetting. In J. M. Golding, \& C. M. MacLeod (Eds.), Intentional forgetting: Interdisciplinary approaches (pp. 103-137). Mahwah, NJ, US: Lawrence Erlbaum Associates Publishers.

Bjork, R. A. (1972). Theoretical implications of directed forgetting. In A. W. Melton \& E. Martin (Eds.), Coding processes in human memory (pp. 217-235). Washington, DC: Winston \& Sons.

Bjork, R. A. (1989). Retrieval inhibition as an adaptive mechanism in human memory. In H. L. Roediger III, \& F. I. M. Craik (Eds.), Varieties of memory and consciousness: Essays in honour of Endel Tulving (pp. 309-330). Hillsdale, NJ: Erlbaum.

Bliese, P. D., Kautz, J., \& Lang, J. W. B. (in press). Discontinuous growth models: Illustrations, recommendations, and an $\mathrm{R}$ function for generating the design matrix. Y. Griep, S. D. Hansen, T. Vantilborgh, T., \& J. Hofmans (Eds.), Handbook of dynamic organizational behavior. Northampton, MA: Edward Elgar.

Bliese, P. D., Adler, A. B., \& Flynn, P. J. (2017). Transition processes: A review and synthesis 
integrating methods and theory. Annual Review of Organizational Psychology and

Organizational Behavior, 4(1), 263-286. doi:10.1146/annurev-orgpsych-032516-113213

Bliese, P. D., Chan, D., \& Ployhart, R. E. (2007). Multilevel methods: Future directions in measurement, longitudinal analyses, and nonnormal outcomes. Organizational Research Methods, 10(4), 551-563. doi:10.1177/1094428107301102

Bliese, P. D., \& Lang, J. W. B. (2016). Understanding relative and absolute change in discontinuous growth models. Organizational Research Methods, 19(4), 562-592. doi:10.1177/1094428116633502

Bliese, P. D., McGurk, D., Thomas, J. L., Balkin, T. J., \& Wesensten, N. (2007). Discontinuous growth modeling of adaptation to sleep setting changes: Individual differences and age. Aviation, Space, and Environmental Medicine, 78(5), 485-492.

Bliese, P. D., \& Ployhart, R. E. (2002). Growth modeling using random coefficient models: Model building, testing, and illustrations. Organizational Research Methods, 5(4), 362387. doi:10.1177/109442802237116

Bröder, A., \& Schiffer, S. (2006). Adaptive flexibility and maladaptive routines in selecting fast and frugal decision strategies. Journal of Experimental Psychology: Learning, Memory, and Cognition, 32(4), 904-918. doi:10.1037/0278-7393.32.4.904

Chan, D. (2000). Conceptual and empirical gaps in research on individual adaptation at work. In C. L. Cooper \& I. T. Robertson (Eds.), International Review of Industrial and Organizational Psychology (pp. 143-164). London: Wiley.

Chan, D. (2014). Organization and management series. Individual adaptability to changes at work: New directions in research (p. 3-17). Routledge/Taylor \& Francis Group. 
Chen, C., Liu, C., Huang, R., Cheng, D., Wu, H., Xu, P., ... Luo, Y.-J. (2012). Suppression of aversive memories associates with changes in early and late stages of neurocognitive processing. Neuropsychologia, 50(12), 2839-2848.

doi:10.1016/j.neuropsychologia.2012.08.004

Cheng, S., Liu, I.-C., Lee, J. R., Hung, D. L., \& Tzeng, O. J.-L. (2012). Intentional forgetting might be more effortful than remembering: An ERP study of item-method directed forgetting. Biological Psychology, 89(2), 283-292. doi:10.1016/j.biopsycho.2011.10.019

Dawis, R. V. (2005). The Minnesota theory of work adjustment. In S. D. Brown \& R. W. Lent (Eds.), Career development and counseling (pp. 3-23). Hoboken, NJ: Wiley.

Depue, B. E., Banich, M. T., \& Curran, T. (2006). Suppression of emotional and non-emotional content in memory. Psychological Science, 17(5), 441-447. doi:10.1111/j.14679280.2006.01725.x

Depue, B. E., Orr, J. M., Smolker, H. R., Naaz, F., \& Banich, M. T. (2015). The organization of right prefrontal networks reveals common mechanisms of inhibitory regulation across cognitive, emotional, and motor processes. Cerebral Cortex, 26(4), 1634-1646. doi:10.1093/cercor/bhu324

Dreisbach, G., \& Bäuml, K.-H. T. (2014). Don’t do it again! Directed forgetting of habits. Psychological Science, 25(6), 1242-1248. doi:10.1177/0956797614526063

Earley, P. C., Wojnaroski, P., \& Prest, W. (1987). Task planning and energy expended: Exploration of how goals influence performance. Journal of Applied Psychology, 72(1), 107-114. doi: 10.1037/0021-9010.72.1.107

Fawcett, J. M., \& Taylor, T. L. (2008). Forgetting is effortful: Evidence from reaction time probes in an item-method directed forgetting task. Memory \& Cognition, 36(6), 1168- 
1181. doi:10.3758/mc.36.6.1168

Fitts, P. M., \& Posner, M. I. (1967). Human performance. Oxford England: Brooks/Cole.

Foster, N. L., \& Sahakyan, L. (2011). The role of forget-cue salience in list-method directed forgetting. Memory, 19(1), 110-117. doi:10.1080/09658211.2010.537665

French, P., \& Sternberg, R. J. (1989). Expertise and intelligent thinking: When is it worse to now better? In R. J. Sternberg (Ed.), Advances in the psychology of human intelligence (pp. 157-188). Hillsdale, NJ: Erlbaum.

Friedman, N. P., \& Miyake, A. (2004). The relations among inhibition and interference control functions: A latent-variable analysis. Journal of Experimental Psychology: General, 133(1), 101-135. doi:10.1037/0096-3445.133.1.101

Gagnepain, P., Henson, R. N., \& Anderson, M. C. (2014). Suppressing unwanted memories reduces their unconscious influence via targeted cortical inhibition. Proceedings of the National Academy of Sciences, 111(13), E1310-E1319. doi:10.1073/pnas.1311468111

Gillund, G., \& Shiffrin, R. M. (1984). A retrieval model for both recognition and recall. Psychological Review, 91(1), 1-67. doi:10.1037/0033-295x.91.1.1

Golding, J. M., \& MacLeod, C. M. (1998). Intentional forgetting: Interdisciplinary approaches. Mahwah, NJ US: Lawrence Erlbaum Associates Publishers.

Griffin, M. A., Neal, A., \& Parker, S. K. (2007). A new model of work role performance: Positive behavior in uncertain and interdependent contexts. Academy of Management Journal, 50(2), 327-347. doi:10.5465/amj.2007.24634438

Griffith, J., Steptoe, A., \& Cropley, M. (1999). An investigation of coping strategies associated with job stress in teachers. British Journal of Educational Psychology, 69(4), 517-531. doi:10.1348/000709999157879 
Hislop, D., Bosley, S., Coombs, C. R., \& Holland, J. (2014). The process of individual unlearning: A neglected topic in an under-researched field. Management Learning, 45(5), 540-560. doi:10.1177/1350507613486423

Holan, P. M. de, \& Phillips, N. (2004). Remembrance of things past? The dynamics of organizational forgetting. Management Science, 50(11), 1603-1613. doi:10.1287/mnsc. 1040.0273

Holyoak, K. J. (1991). Symbolic connectionism: Toward third-generation theories of expertise. In K. A. Ericsson and J. Smith (eds.), Toward a general theory of expertise: 301-336. Cambridge, uK: Cambridge University Press.

Hommel, B. (2000). The prepared reflex: Automaticity and control in stimulus-response translation. In S. Monsell, \& J. Driver (Eds.), Control of cognitive processes: Attention and Performance, Vol. XVIII (pp. 247-273). Cambridge, MA: MIT Press.

Howe, M. (2019). General mental ability and goal type as antecedents of recurrent adaptive task performance. Journal of Applied Psychology,796-813, doi.org/10.1037/ap10000379

Ilgen, D. R., \& Pulakos, E. D. (1999). Employee performance in today’s organizations. In D. R. Ilgen \& E. D. Pulakos (Eds.), The changing nature of performance: Implications for staffing, motivation, an development (pp. 21-55). San Francisco: Jossey-Bass.

Joormann, J., Hertel, P. T., Brozovich, F., \& Gotlib, I. H. (2005). Remembering the good, forgetting the bad: Intentional forgetting of emotional material in depression. Journal of Abnormal Psychology, 114(4), 640-648. doi:10.1037/0021-843x.114.4.640

Joslyn, S. L., \& Oakes, M. A. (2005). Directed forgetting of autobiographical events. Memory \& Cognition, 33(4), 577-587. doi:10.3758/bf03195325

Jundt, D.K., Shoss, M.K., \& Huang, J.L. (2014). Individual adaptive performance in 
organizations: A review. Journal of Organizational Behavior, 1099-1379.

doi:10.1002/job.1955

Kanfer, R., \& Ackerman, P. L. (1989). Motivation and cognitive abilities: An integrative/aptitude-treatment interaction approach to skill acquisition. Journal of Applied Psychology, 74(4), 657-690. doi:10.1037/0021-9010.74.4.657

Kluge, A., \& Gronau, N. (2018). Intentional forgetting in organizations: The importance of eliminating retrieval cues for implementing new routines. Frontiers in Psychology, 9. doi:10.3389/fpsyg.2018.00051

Labianca, G., Gray, B., \& Brass, D. J. (2000). A Grounded Model of Organizational Schema Change During Empowerment. Organization Science, 11(2), 235-257. doi:10.1287/orsc.11.2.235.12512

Lang, J. W. B., \& Bliese, P. D. (2009). General mental ability and two types of adaptation to unforeseen change: Applying discontinuous growth models to the task-change paradigm. Journal of Applied Psychology, 94(2), 411-428. doi:10.1037/a0013803

Lang, J. W. B., Bliese, P. D. \& Runge, J. M. (in press). Detecting consensus emergence in organizational multilevel data: Power simulations. Organizational Research Methods. https://doi.org/10.1177/1094428119873950

Lehman, M., \& Malmberg, K. J. (2009). A global theory of remembering and forgetting from multiple lists. Journal of Experimental Psychology: Learning, Memory, and Cognition, 35(4), 970-988. doi:10.1037/a0015728

LePine, J. A., Colquitt, J. A., \& Erez, A. (2000). Adaptability to changing task contexts: Effects of general cognitive ability, conscientiousness, and openness to experience. Personnel Psychology, 53(3), 563-593. doi:10.1111/j.1744-6570.2000.tb00214.x 
Levy, B. J., \& Anderson, M. C. (2008). Individual differences in the suppression of unwanted memories: The executive deficit hypothesis. Acta Psychologica, 127(3), 623-635. doi:10.1016/j.actpsy.2007.12.004

Logan, G. D. (1988). Toward an instance theory of automatization. Psychological Review, 95(4), 492-527. doi:10.1037/0033-295X.95.4.492

Magee, L. (1990). R2 measures based on wald and likelihood ratio joint significance tests. The American Statistician, 44, 250-253. https://doi.org/10.1080/00031305.1990.10475731

Matuschek, H., Kliegl, R., Vasishth, S., Baayen, R. H., and Bates, D. (2017). Balancing type I error and power in linear mixed models. Journal of Memory and Language, 94, 305-315. https://www.sciencedirect.com/science/article/pii/S0749596X17300013

MacLeod, C. M. (1999). The item and list methods of directed forgetting: Test differences and the role of demand characteristics. Psychonomic Bulletin \& Review, 6, 123-129.

Mensink, G.-J., \& Raaijmakers, J. G. (1988). A model for interference and forgetting. Psychological Review, 95(4), 434-455. doi:10.1037/0033-295x.95.4.434

Miyake, A., Friedman, N. P., Emerson, M. J., Witzki, A. H., Howerter, A., \& Wager, T. D. (2000). The unity and diversity of executive functions and their contributions to complex "frontal lobe" tasks: a latent variable analysis. Cognitive Psychology, 41(1), 49-100. doi:10.1006/cogp.1999.0734

Niessen, C., \& Jimmieson, N. L. (2016). Threat of resource loss: The role of self-regulation in adaptive task performance. Journal of Applied Psychology, 101(3), 450-462. doi:10.1037/ap10000049

Nørby, S. (2015). Why Forget? On the Adaptive Value of Memory Loss. Perspectives on Psychological Science, 10(5), 551-578. doi:10.1177/1745691615596787 
Noreen, S., \& MacLeod, M. D. (2013). It's all in the detail: Intentional forgetting of autobiographical memories using the autobiographical think/no-think task. Journal of Experimental Psychology: Learning, Memory, and Cognition, 39(2), 375-393. doi:10.1037/a0028888

Noreen, S., \& MacLeod, M. D. (2014). To think or not to think, that is the question: Individual differences in suppression and rebound effects in autobiographical memory. Acta Psychologica, 145, 84-97. doi:10.1016/j.actpsy.2013.10.011

Ployhart, R. E., \& Bliese, P. D. (2006). Individual adaptability (I-ADAPT) theory: Conceptualizing the antecedents, consequences, and measurement of individual differences in adaptability. In C. S. Burke, L. G. Pierce \& E. Salas (Eds.), Understanding adaptability: A prerequisite for effective performance within complex environments ( $\mathrm{pp}$. 3-39). Amsterdam, Netherlands: Elsevier.

Pulakos, E. D., Arad, S., Donovan, M. A., \& Plamondon, K. E. (2000). Adaptability in the workplace: Development of a taxonomy of adaptive performance. Journal of Applied Psychology, 85(4), 612-624. doi:10.1037/0021-9010.85.4.612

Pulakos, E. D., Schmitt, N., Dorsey, D. W., Arad, S., Borman, W. C., \& Hedge, J. W. (2002). Predicting adaptive performance: Further tests of a model of adaptability. Human Performance, 15(4), 299-323. doi:10.1207/s15327043hup1504_01

R Core Team. (2018). R: A language and environment for statistical computing [Version 3.5.0]. Vienna, Austria: R Foundation for Statistical Computing. Retrieved from http://www.rproject.org

Sahakyan, L., \& Delaney, P. F. (2005). Directed forgetting in incidental learning and recognition testing: Support for a two-factor account. Journal of Experimental Psychology: Learning, 
Memory, and Cognition, 31(4), 789-801. doi:10.1037/0278-7393.31.4.789

Sahakyan, L., \& Delaney, P. F. (2003). Can encoding differences explain the benefits of directed forgetting in the list method paradigm? Journal of Memory and Language, 48(1), 195206. doi:10.1016/s0749-596x(02)00524-7

Sahakyan, L., Delaney, P. F., \& Kelley, C. M. (2004). Self-evaluation as a moderating factor of strategy change in directed forgetting benefits. Psychonomic Bulletin \& Review, 11(1), 131-136. doi:10.3758/bf03206472

Sahakyan, L., \& Foster, N. L. (2009). Intentional forgetting of actions: Comparison of listmethod and item-method directed forgetting. Journal of Memory and Language, 61(1), 134-152. doi:10.1016/j.jml.2009.02.006

Sahakyan, L., \& Kelley, C. M. (2002). A contextual change account of the directed forgetting effect. Journal of Experimental Psychology: Learning, Memory, and Cognition, 28(6), 1064-1072. doi:10.1037/0278-7393.28.6.1064

Sahakyan, L., Delaney, P. F., Foster, N. L., \& Abushanab, B. (2013). List-method directed forgetting in cognitive and clinical research. Psychology of Learning and Motivation, 131-189. doi:10.1016/b978-0-12-407187-2.00004-6

Schmeichel, B. J. (2007). Attention control, memory updating, and emotion regulation temporarily reduce the capacity for executive control. Journal of Experimental Psychology: General, 136(2), 241-255. doi:10.1037/0096-3445.136.2.241

Schunn, C. D., \& Reder, L. M. (2001). Another source of individual differences: Strategy adaptivity to changing rates of success. Journal of Experimental Psychology: General, 130(1), 59-76. doi:10.1037/0096-3445.130.1.59

Shapiro, S., Lindsey, C., \& Krishnan, H. S. (2006). Intentional forgetting as a facilitator for 
recalling new product attributes. Journal of Experimental Psychology: Applied, 12(4), 251-263. doi:10.1037/1076-898x.12.4.251

Shiffrin, R. M., \& Steyvers, M. (1997). A model for recognition memory: REM-retrieving effectively from memory. Psychonomic Bulletin \& Review, 4(2), 145-166. doi:10.3758/bf03209391

Singer, J. D., \& Willett, J. B. (2003). Applied longitudinal data analysis: Modeling change and event occurrence. New York, NY, US: Oxford University Press, 2003.

Stephens, E., Braid, A., \& Hertel, P. T. (2013). Suppression-induced reduction in the specificity of autobiographical memories. Clinical Psychological Science, 1(2), 163-169. doi:10.1177/2167702612467773

Tsang, E. W. K. (2008). Transferring knowledge to acquisition joint ventures: An organizational unlearning perspective. Management Learning, 39(1), 5-20.

doi:10.1177/1350507607085169

Tulving, E. (1974). Cue-dependent forgetting. American Scientist, 62(1), 74-82. Retrieved from http://www.jstor.org/stable/27844717

Van Schie, K., Geraerts, E., \& Anderson, M. C. (2013). Emotional and non-emotional memories are suppressible under direct suppression instructions. Cognition \& Emotion, 27(6), 1122-1131. doi:10.1080/02699931.2013.765387

Yang, T., Lei, X., \& Anderson, M. (2016). Decreased inhibitory control of negative information in directed forgetting. International Journal of Psychophysiology, 100, 44-51. doi:10.1016/j.ijpsycho.2015.09.007

Yeo, G. B., \& Neal, A. (2004). A multilevel analysis of effort, practice, and performance: Effects of ability, conscientiousness, and goal orientation. Journal of Applied Psychology, 89(2), 
231-247. doi:10.1037/0021-9010.89.2.231 
Table 1

Rule sets and distractor rules from the final recognition test

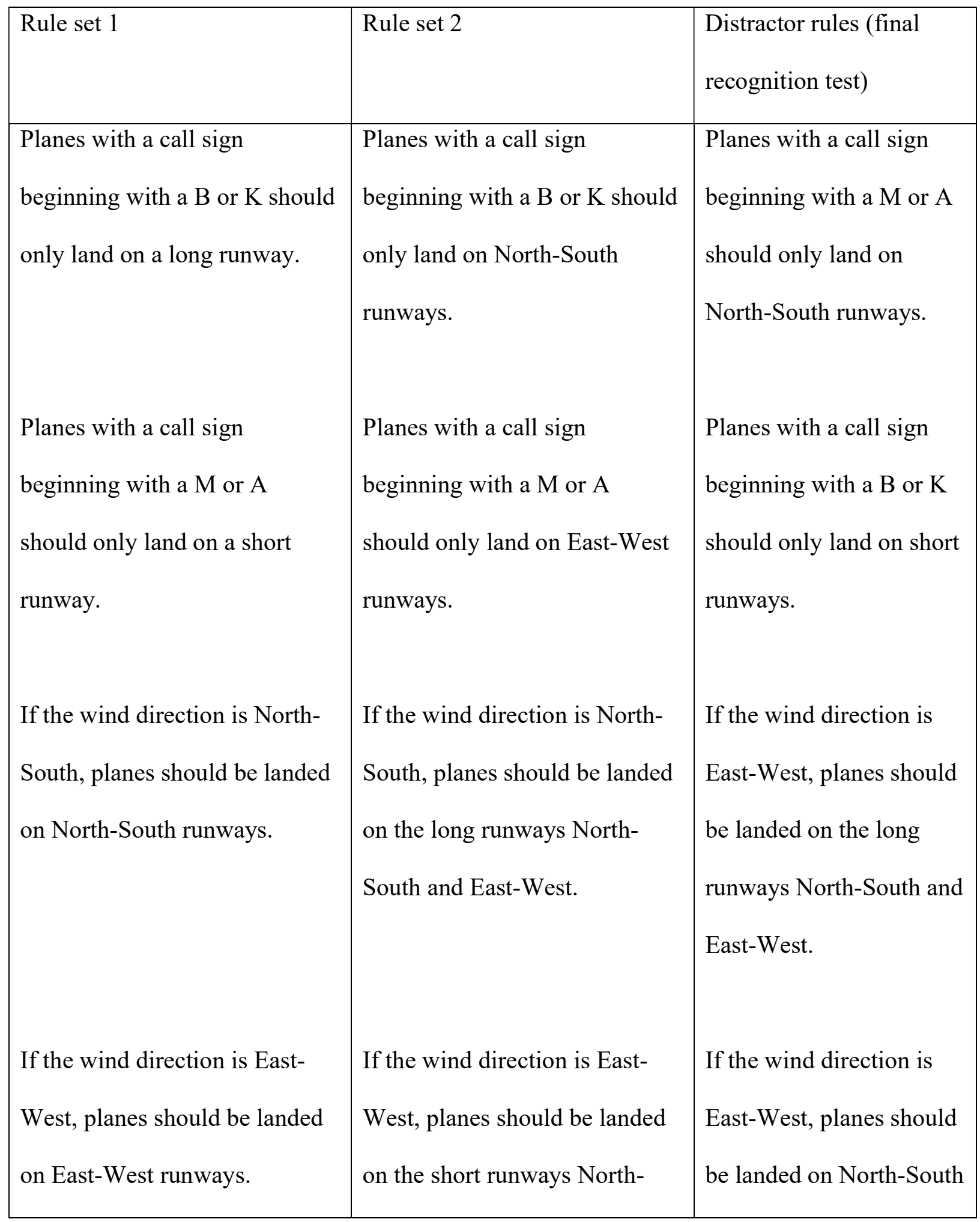




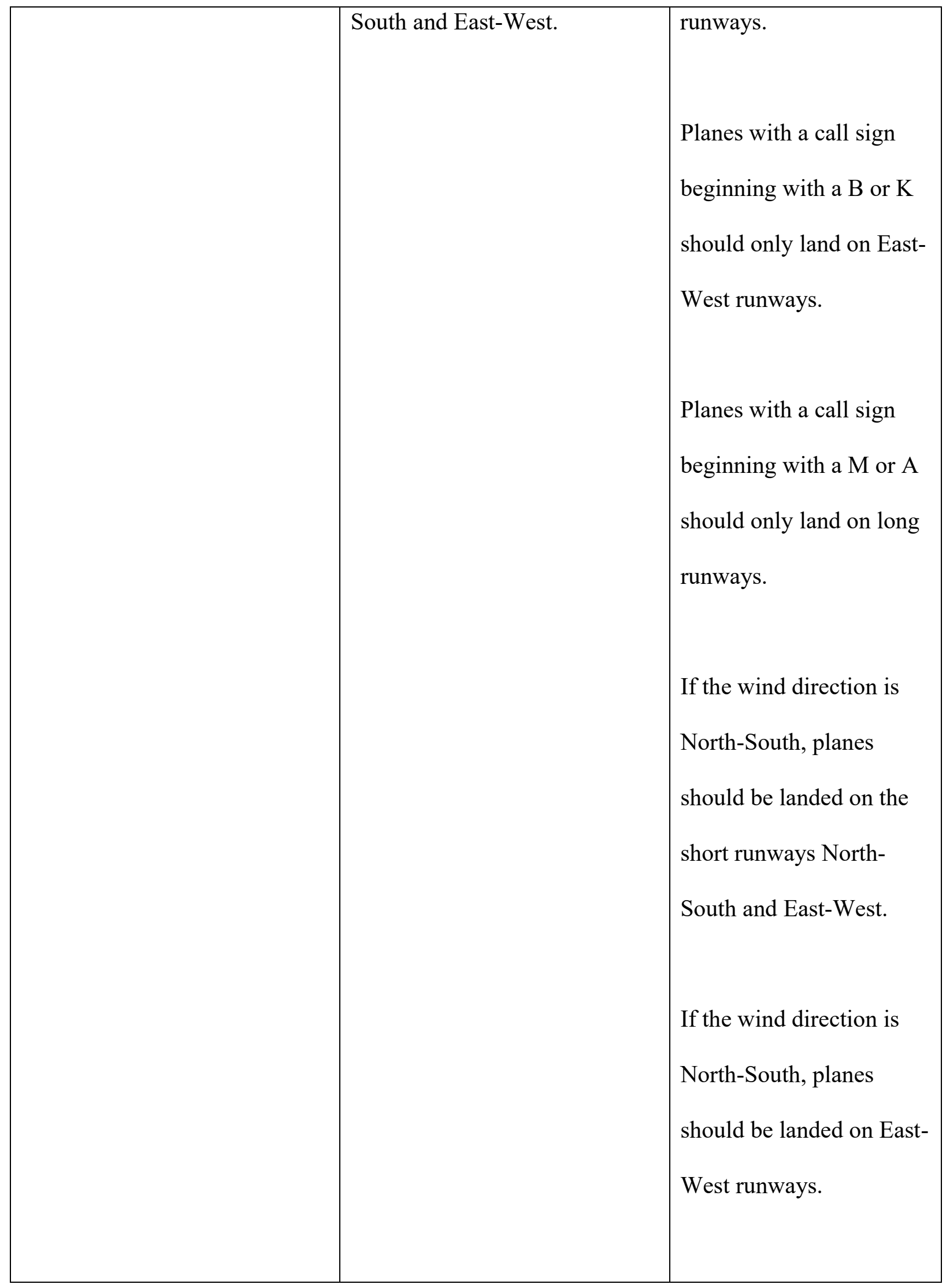


Table 2

Means, Standard Deviations, and Intercorrelations of the Study Variables of Experiment 1

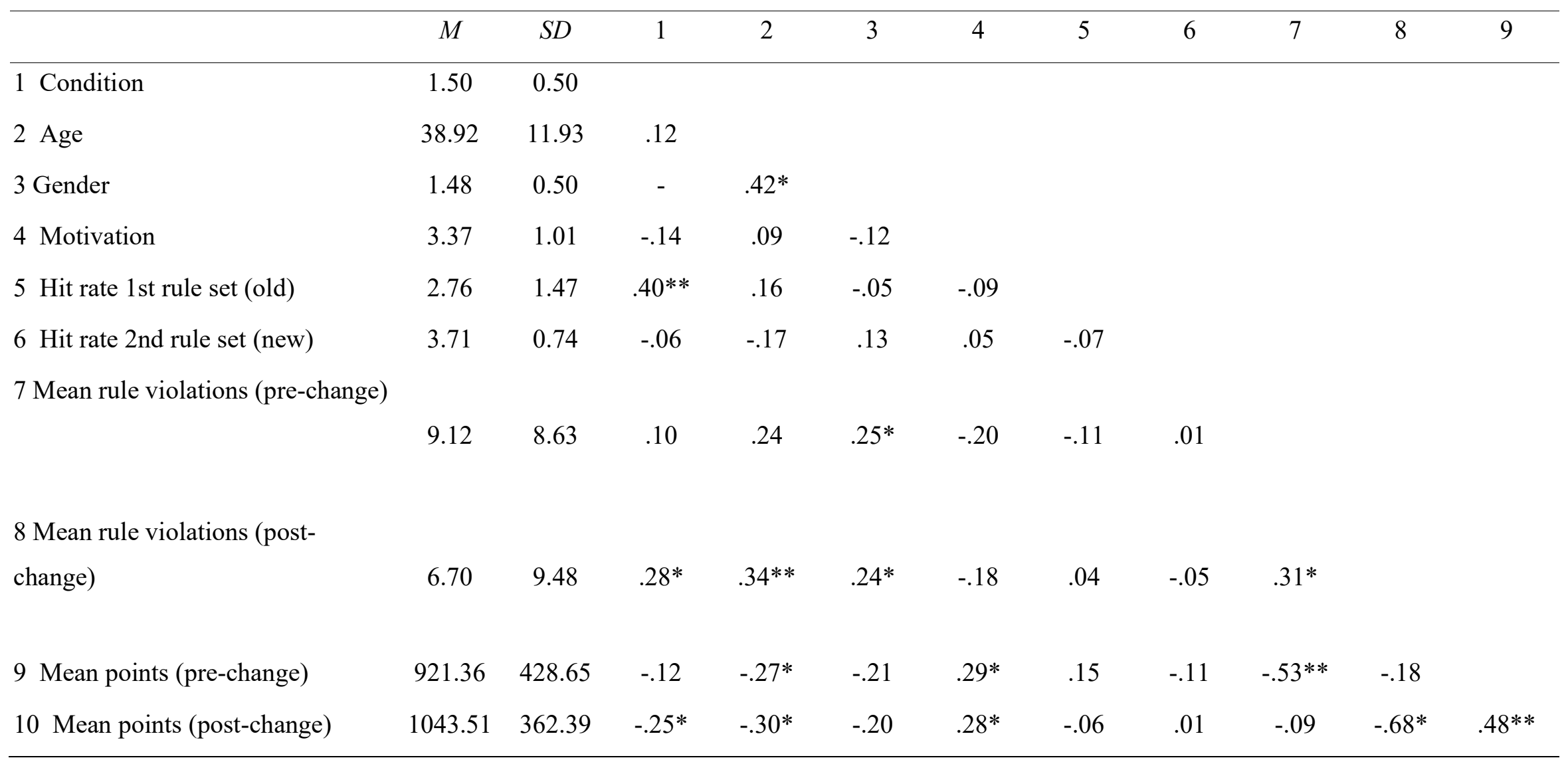

Note. Instruction is coded as follows: $1=$ forget $2=$ remember. Gender is coded $1=$ female $2=$ male $(N=66)$. 
Table 3

Results of the Manipulation Check and the Unexpected Recognition Test (End of the Experiment, Study 1 and 2)

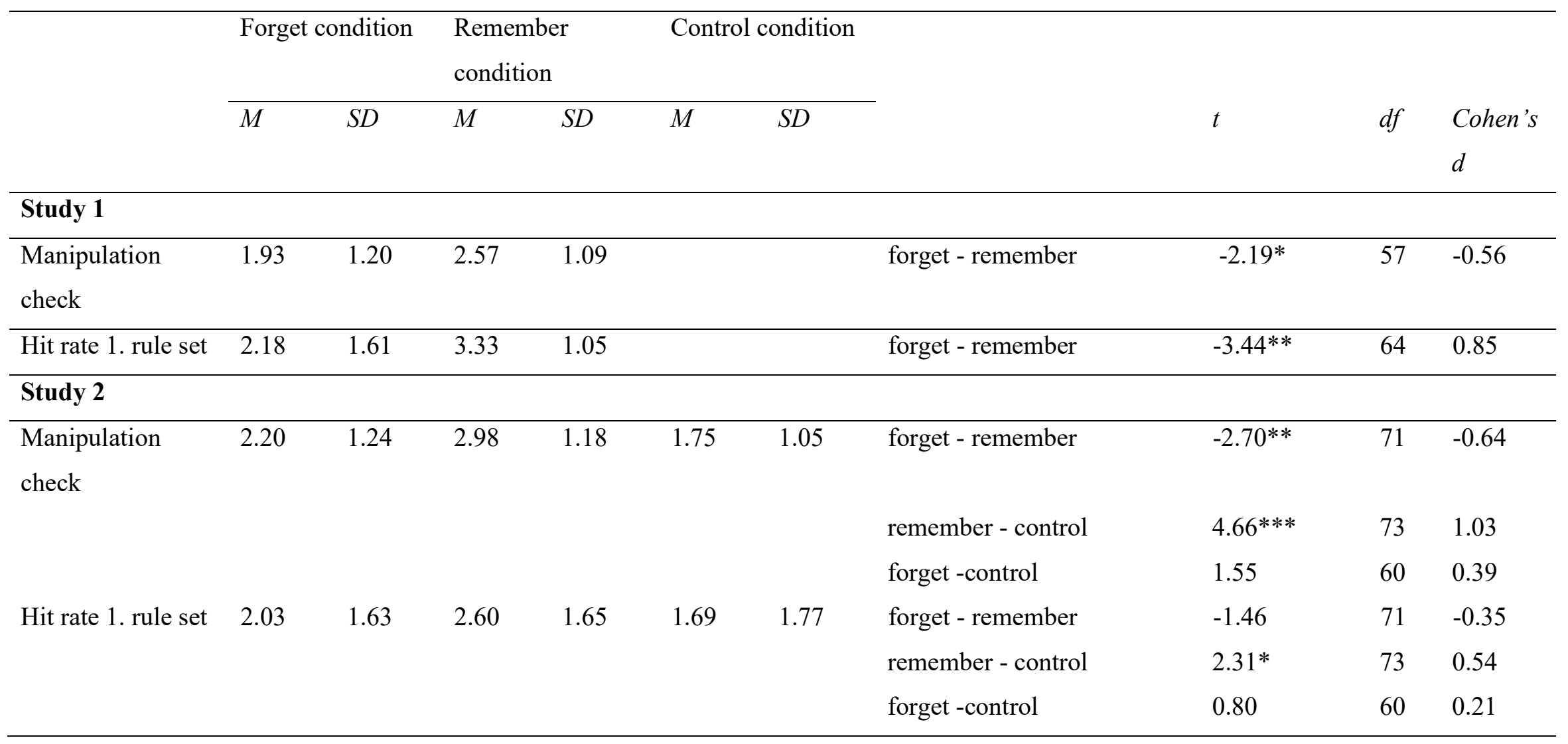


Table 4

Coding of the Change Variables in the Discontinuous Mixed-Effects Growth Models for Study 1

\begin{tabular}{|c|c|c|c|c|c|c|c|c|c|c|c|c|c|c|c|c|c|c|c|c|}
\hline \multirow[b]{2}{*}{ Change variables } & \multicolumn{20}{|c|}{ Measurement occasions } \\
\hline & 1 & 2 & 3 & 4 & 5 & 6 & 7 & 8 & 9 & 10 & 11 & 12 & 13 & 14 & 15 & 16 & 17 & 18 & 19 & 20 \\
\hline \multicolumn{21}{|l|}{ Study 1} \\
\hline Skill acquisition (SA) & 0 & 1 & 2 & 3 & 4 & 5 & 6 & 7 & 8 & 9 & 9 & 9 & 9 & 9 & 9 & 9 & 9 & 9 & 9 & 9 \\
\hline Transition adaptation (TA) & 0 & 0 & 0 & 0 & 0 & 0 & 0 & 0 & 0 & 0 & 1 & 1 & 1 & 1 & 1 & 1 & 1 & 1 & 1 & 1 \\
\hline $\begin{array}{l}\text { Reacquisition adaptation } \\
\text { (RA) }\end{array}$ & 0 & 0 & 0 & 0 & 0 & 0 & 0 & 0 & 0 & 0 & 0 & 1 & 2 & 3 & 4 & 5 & 6 & 7 & 8 & 9 \\
\hline $\begin{array}{l}\text { Quadratic skill acquisition } \\
\left(\mathrm{SA}^{2}\right)\end{array}$ & 0 & 1 & 4 & 9 & 16 & 25 & 36 & 49 & 64 & 81 & 81 & 81 & 81 & 81 & 81 & 81 & 81 & 81 & 81 & 81 \\
\hline $\begin{array}{l}\text { Quadratic reacquisition } \\
\text { adaptation }\left(\mathrm{RA}^{2}\right)\end{array}$ & 0 & 0 & 0 & 0 & 0 & 0 & 0 & 0 & 0 & 0 & 0 & 1 & 4 & 9 & 16 & 15 & 36 & 49 & 64 & 81 \\
\hline Study 2 & & & & & & & & & & & & & & & & & & & & \\
\hline SA & 0 & 1 & 2 & 3 & 4 & 5 & 6 & 7 & 7 & 7 & 7 & 7 & 7 & 7 & 7 & 7 & & & & \\
\hline TA & 0 & 0 & 0 & 0 & 0 & 0 & 0 & 0 & 1 & 1 & 1 & 1 & 1 & 1 & 1 & 1 & & & & \\
\hline
\end{tabular}


COGNITIVE CONTROL AND ADAPTIVE PERFORMANCE

RA

$\begin{array}{cccccccccccccccc}0 & 0 & 0 & 0 & 0 & 0 & 0 & 0 & 0 & 1 & 2 & 3 & 4 & 5 & 6 & 7 \\ 0 & 1 & 4 & 9 & 16 & 25 & 36 & 49 & 49 & 49 & 49 & 49 & 49 & 49 & 49 & 49 \\ 0 & 0 & 0 & 0 & 0 & 0 & 0 & 0 & 0 & 1 & 4 & 9 & 16 & 25 & 36 & 49\end{array}$

Note. Coding based on Bliese and Lang (2016) 
Table 5

Discontinuous Growth Modeling Analyses Testing the Impact of the Change and Experimental Condition on Rule Violations and Performance (points) -

Experiment 1

\begin{tabular}{|c|c|c|c|c|c|c|}
\hline \multirow{2}{*}{$\begin{array}{l}\text { DV } \\
\text { Value }\end{array}$} & \multicolumn{3}{|c|}{ Rule Violations } & \multicolumn{3}{|c|}{ Points } \\
\hline & Null model & Model 1 & Model 2 & Null model & Model 1 & Model 2 \\
\hline \multicolumn{7}{|l|}{ Coefficients $(S E)$} \\
\hline Intercept & $12.01(1.29)^{* *}$ & $35.01(2.11)^{* *}$ & $35.01(2.11)^{* *}$ & $982.44(41.86)^{* *}$ & $450.76(67.80)^{* *}$ & $450.76(67.78)^{* *}$ \\
\hline Skill acquisition (SA) & & $-9.35(0.57)^{* *}$ & $-9.35(0.57)^{* *}$ & & $226.29(17.88)^{* *}$ & $226.29(17.86)^{* *}$ \\
\hline Quadratic SA & & $0.70(0.06)^{* *}$ & $0.70(0.06)^{* *}$ & & $-17.40(1.91)^{* *}$ & $-17.40(1.91)^{* *}$ \\
\hline Transition adaptation (TA) & & $9.43(1.68)^{* *}$ & $8.96(1.97)^{* *}$ & & $-150.64(52.67)^{* *}$ & $-87.03(61.38)$ \\
\hline Reacquisition adaptation (RA) & & $-5.12(0.57)^{* *}$ & $-4.97(0.81)^{* *}$ & & $91.64(17.88)^{* *}$ & $66.17(25.26)^{* *}$ \\
\hline Quadratic RA & & $0.41(0.06)^{* *}$ & $0.40(0.09)^{* *}$ & & $-7.25(1.91)^{* *}$ & $-5.46(2.70)^{* *}$ \\
\hline Condition ( 1 = forgetting, & & $2.92(2.61)$ & $2.92(2.61)$ & & $-103.76(84.80)$ & $-103.76(84.79)$ \\
\hline \multicolumn{7}{|l|}{$0=$ remembering) } \\
\hline TA $\times$ condition & & $4.04(1.26)^{* *}$ & $4.98(2.38)^{*}$ & & $-75.818(39.308) \dagger$ & $-203.03(74.41)^{* *}$ \\
\hline $\mathrm{RA} \times$ condition & & & $-0.31(1.14)$ & & & $50.94(35.72)$ \\
\hline Quadratic RA $\times$ condition & & & $0.02(0.12)$ & & & $-3.58(3.82)$ \\
\hline
\end{tabular}


Random effect $S D$ s

\begin{tabular}{|c|c|c|c|c|c|c|}
\hline Person & 10.02 & 9.98 & 9.98 & 327.69 & 325.42 & 325.45 \\
\hline Residual & 14.28 & 11.41 & 11.42 & 406.40 & 357.03 & 356.65 \\
\hline Intra-class correlation (ICC) & .33 & & & .39 & & \\
\hline Log-likelihood & $-5,459.36$ & $-5,175.80$ & $-5,177.08$ & $-9,884.64$ & $-9,695.81$ & $-9,688.05$ \\
\hline Model $d f \mathrm{~s}$ & 3 & 10 & 12 & 3 & 10 & 12 \\
\hline$R_{\mathrm{LR}^{2}}$ & .419 & .592 & .592 & .286 & .596 & .596 \\
\hline
\end{tabular}

Note. $\mathrm{DV}=$ dependent variable. $N=66$ persons, and $k=1320$ observations. $R_{\mathrm{LR}}{ }^{2}=1$-exp(-2/N $\left.\times\left[L_{0}-L_{\mathrm{M}}\right]\right)$ where $L_{0}$ and $L_{\mathrm{M}}$ refer to the log-likelihood estimated using maximum likelihood estimation for a null model without any effects (also omitting random effects) and of the model of interest, respectively (Lang, Bliese, \& Runge, in press; Magee, 1990).

$\dagger p<-.10 * p<.05 * * p<.01$ 
Table 6

Means, Standard Deviations, and Intercorrelations of the Study Variables of Experiment 2

\begin{tabular}{|c|c|c|c|c|c|c|c|c|c|c|c|c|c|}
\hline & $M$ & $S D$ & 1 & 2 & 3 & 4 & 5 & 6 & 7 & 8 & 9 & 10 & 11 \\
\hline 1 Condition 1 & 0.32 & 0.46 & & & & & & & & & & & \\
\hline 2 Condition 2 & 0.29 & 0.45 & $-.42 * *$ & & & & & & & & & & \\
\hline 3 Age & 22.80 & 5.49 & -.09 & .13 & & & & & & & & & \\
\hline 4 Gender & 1.28 & 0.47 & .051 & -.15 & .08 & & & & & & & & \\
\hline 5 Motivation & 2.76 & 0.88 & -.13 & -.06 & -.01 & -.09 & & & & & & & \\
\hline 6 Effort & 3.79 & 0.68 & .02 & -.11 & -.04 & $-.20 *$ & $.38 * *$ & & & & & & \\
\hline $\begin{array}{l}7 \text { Hit rate } 1 \text { st rule set } \\
\text { (old) }\end{array}$ & 2.16 & 1.71 & -.19 & -.05 & -.07 & -.08 & .10 & .02 & & & & & \\
\hline $\begin{array}{l}8 \text { Hit rate } 2 \text { nd rule set } \\
\text { (new) }\end{array}$ & 3.65 & 0.72 & .07 & .08 & -.09 & -.12 & -.13 & -.16 & .12 & & & & \\
\hline $\begin{array}{l}9 \text { Mean rule violations } \\
\text { (pre-change) }\end{array}$ & 9.60 & 10.82 & .06 & -.09 & -.01 & .003 & -.18 & .00 & -.09 & -.09 & & & \\
\hline $\begin{array}{l}10 \text { Mean rule violations } \\
\text { (post-change) }\end{array}$ & 7.28 & 10.76 & -.17 & -.15 & .06 & -.06 & -.05 & -.02 & .06 & $-.27 * *$ & $.50 * *$ & & \\
\hline $\begin{array}{l}11 \text { Mean points (pre- } \\
\text { change) }\end{array}$ & 878.39 & 483.38 & .07 & .02 & $-.31 * *$ & .13 & $.21 *$ & $.23 *$ & -.08 & -.03 & $-.50 * *$ & $-.47 * *$ & \\
\hline $\begin{array}{l}12 \text { Mean points (post- } \\
\text { change) }\end{array}$ & 1018.64 & 398.20 & .15 & .07 & $-.24 *$ & .13 & .14 & $-24^{*}$ & -.13 & .06 & $-.27 * *$ & $-.62 * *$ & $.88 * *$ \\
\hline
\end{tabular}

Note. $N=105$. Condition 1 ( $1=$ control, $0=$ remembering $)$, Condition $2(1=$ forgetting, $0=$ remembering $)$. Gender is coded $1=$ female $2=$ male. 
Table 7

Discontinuous Growth Modeling Analyses Testing the Impact of the Change and Experimental Condition on Rule Violations and Performance (points) -

Experiment 2

\begin{tabular}{|c|c|c|c|c|c|c|}
\hline $\mathrm{DV}$ & & Rule Violations & & & Points & \\
\hline Value & Null model & Model 1 & Model 2 & Null model & Model 1 & Model 2 \\
\hline \multicolumn{7}{|l|}{ Coefficients (SE) } \\
\hline Intercept & $15.59(1.37)^{* *}$ & $46.52(2.37)^{* *}$ & $\begin{array}{r}46.52 \\
(2.37)^{* *}\end{array}$ & $948.52(41.69)^{* *}$ & $-267.65(70.82)^{* *}$ & $-267.65(70.82)^{* *}$ \\
\hline Skill acquisition (SA) & & $-13.83(0.68)^{* *}$ & $-13.83(0.68)^{* *}$ & & $-312.13(18.27)^{* *}$ & $-312.13(18.27)^{* *}$ \\
\hline Quadratic SA & & $1.25(0.09)^{* *}$ & $1.25(0.09)^{* *}$ & & $-30.19(2.51)^{* *}$ & $-30.19(2.51)^{* *}$ \\
\hline Transition adaptation (TA) & & $18.91(1.61)^{* *}$ & $19.62(1.96)^{* *}$ & & $-276.18(43.36)^{* *}$ & $-283.48(52.64)^{* *}$ \\
\hline Reacquisition adaptation (RA) & & $-7.91(0.68)^{* *}$ & $-8.33(1.06)^{* *}$ & & $129.31(18.27)^{* *}$ & $130.84(28.55)^{* *}$ \\
\hline Quadratic RA & & $0.80(0.09)^{* *}$ & $0.84(0.15)^{* *}$ & & $-12.98(2.51)^{* *}$ & $-12.87(3.92)^{* *}$ \\
\hline Condition 1 ( 1 = control, & & $-2.68(3.40)$ & $-2.68(3.40)$ & & $97.12(101.52)^{* *}$ & $97.12(101.52)^{* *}$ \\
\hline \multicolumn{7}{|l|}{$0=$ remembering) } \\
\hline Condition 2 ( 1 = forgetting, & & $-0.41(3.34)$ & $-0.41(3.37)$ & & $59.26(103.45)$ & $59.26(103.45)$ \\
\hline
\end{tabular}


$0=$ remembering)

TA $\times$ dummy 1

TA $\times$ dummy 2

RA $\times$ dummy 1

RA $\times$ dummy 1

Quadratic RA $\times$ dummy 1

Quadratic RA $\times$ dummy 2

\section{Random effect $S D$ s}

\section{Person}

Residual

Intra-class correlation (ICC)

Log-likelihood

Model $d f \mathrm{~s}$

$R_{\mathrm{LR}}^{2}$

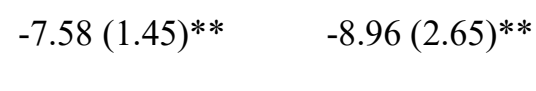

$-4.18(1.48)^{* *}$

$-5.20(2.70) \dagger$

$0.81(1.63)$

$0.60(1.66)$

$-0.08(0.22)$

$-0.06(0.22)$

13.35

16.76

.39

$-7,244.40$

3

.419
13.60

12.41

$-6,763.30$

12
13.60

12.42

.592
$88.54(38.91)^{* *}$

$78.38(39.64)^{*}$

$155.39(71.05)^{*}$

32.61 (72.39)

$-32.78(43.71)$

$29.62(44.54)$

$2.74(6.00)$

$-3.31(6.12)$

Note. $\mathrm{DV}=$ dependent variable. $N=105$ persons, and $k=1680$ observations. $R_{\mathrm{LR}}{ }^{2}=1-\exp \left(-2 / \mathrm{N} \times\left[L_{0}-L_{\mathrm{M}}\right]\right)$ where $L_{0}$ and $L_{\mathrm{M}}$ refer to the log-likelihood estimated

\& Runge, in press; Magee, 1990).

$\dagger p<-.10 * p<.05 * * p<.01$ 


\section{Figure Captions}

Figure 1. Screen of the air traffic control simulation.

Figure 2. Experimental procedure.

Figure 3. Plots for rule violations and performance (points) as a function of change and experimental condition (Experiment 1). Rule violations: (A) group means, (B) predicted values. Performance (points): (C) group means, (D) predicted values.

Figure 4. Plots for rule violations and performance (points) as a function of change and experimental condition (Experiment 2). Rule violations: (A) group means, (B) predicted values. Performance (points): (C) group means, (D) predicted values. 


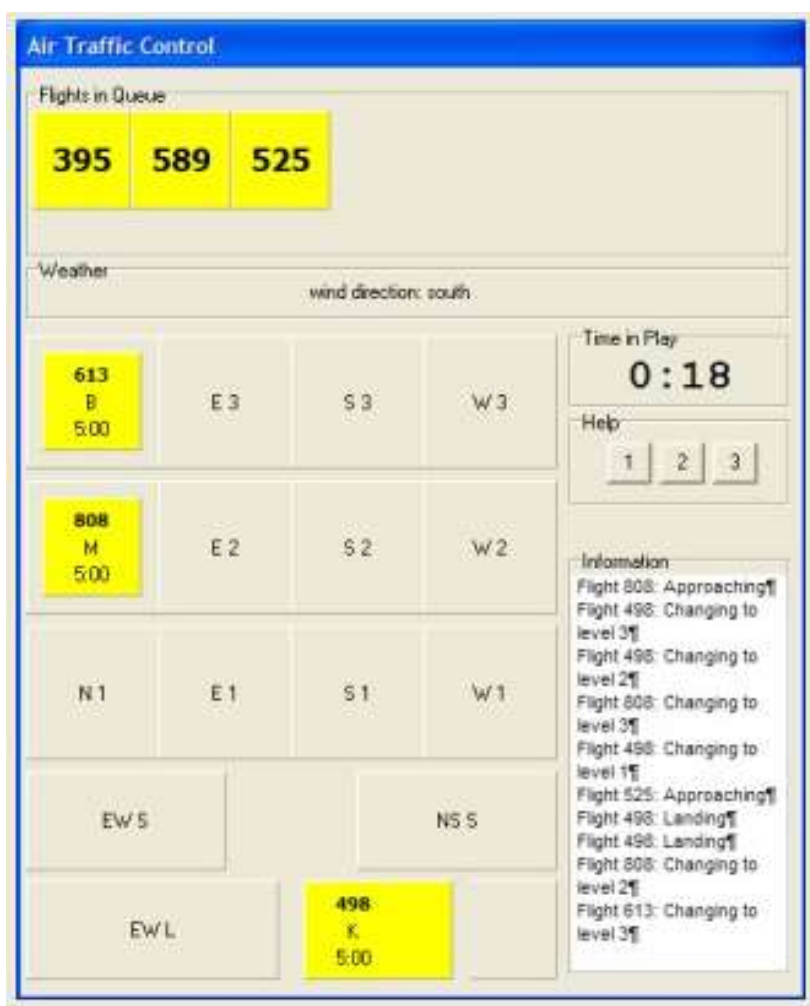




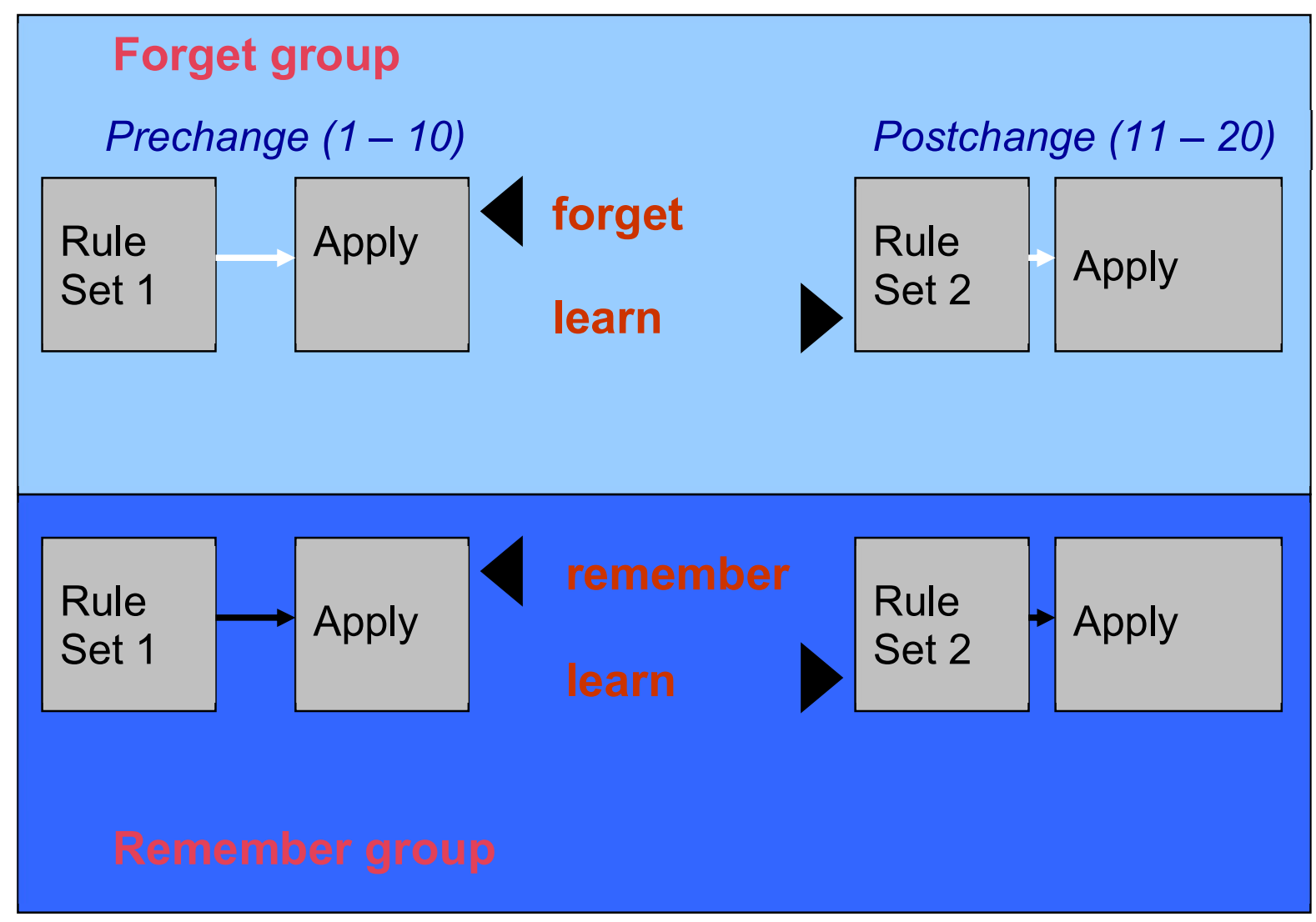

Recognition test of both rule sets 
A

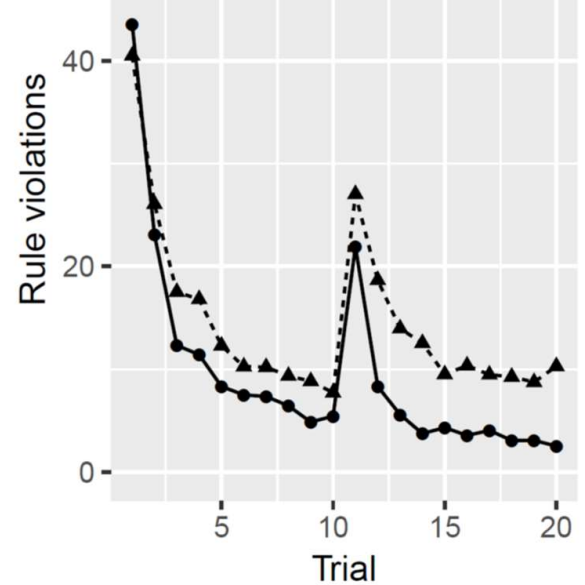

C

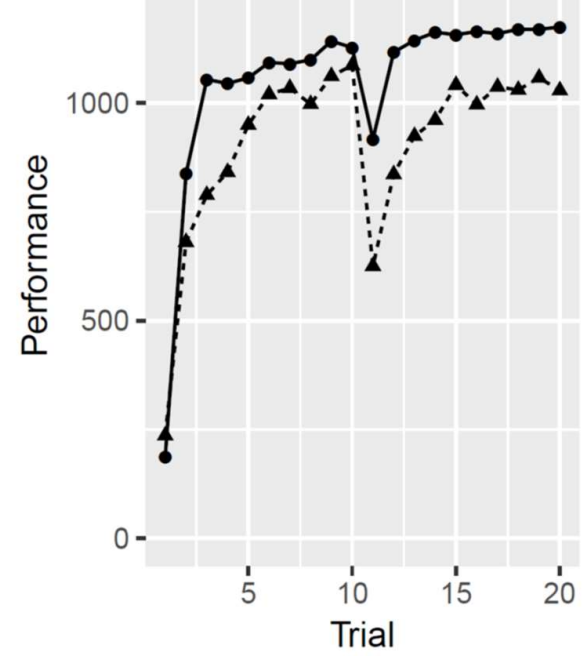

B

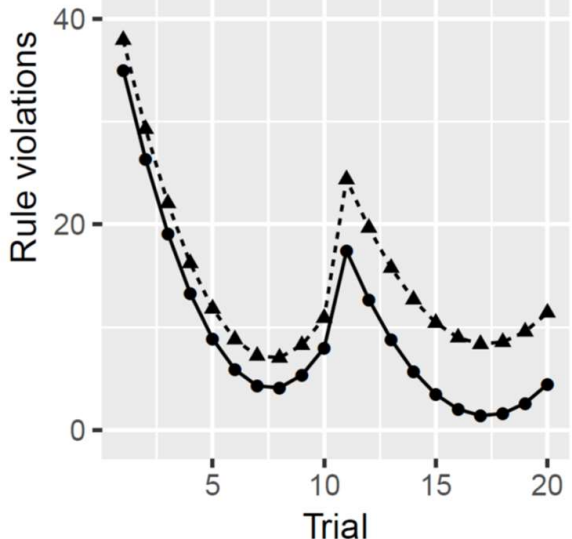

D

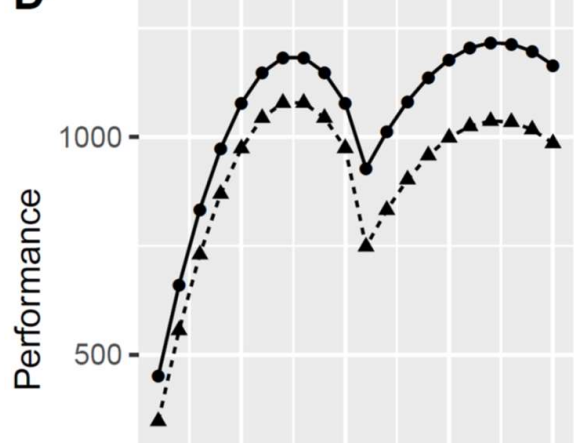

$\rightarrow$ Forgetting

- $\_$Remembering

$0-$

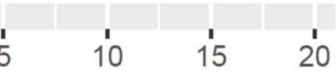

Trial 
A

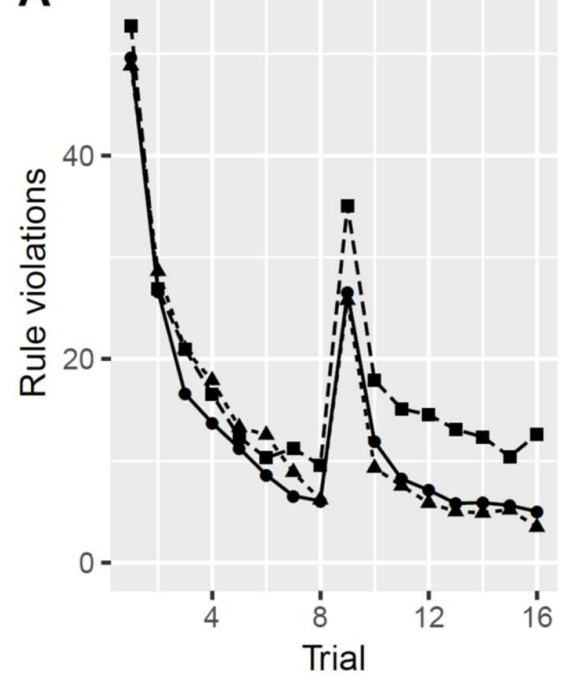

C

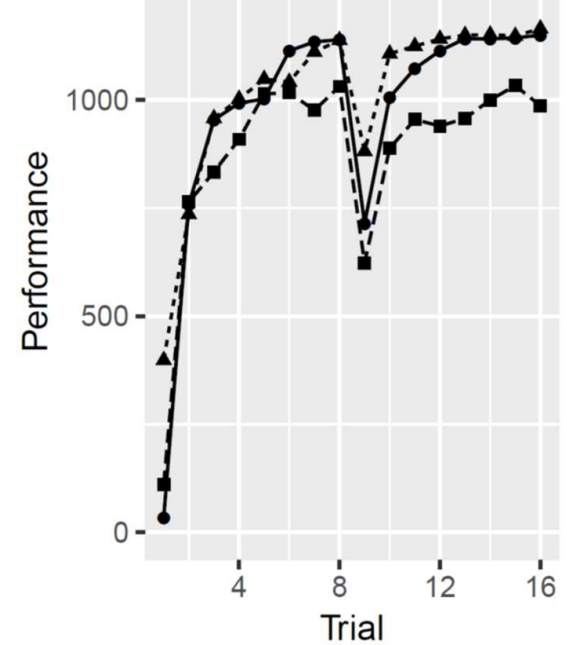

B

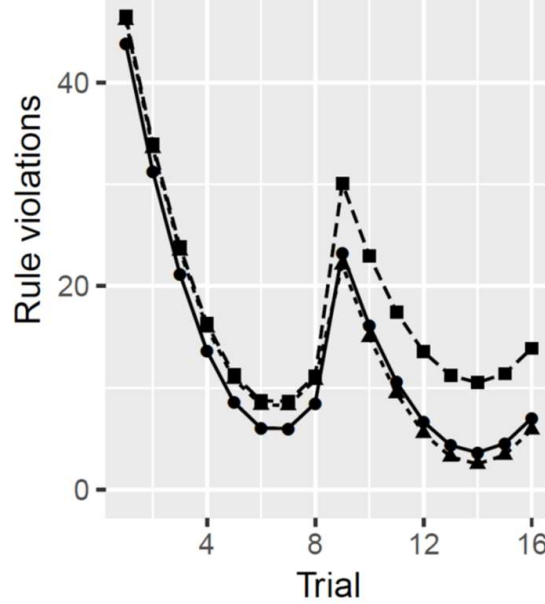

D

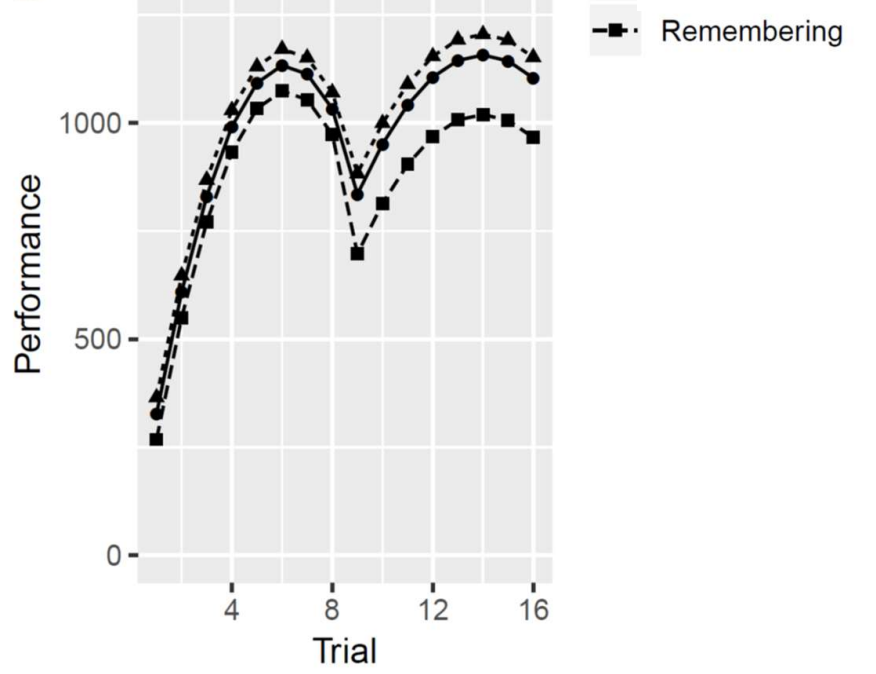

Condition

$\rightarrow$ Explicit forgetting

-^. Control instruction 


\section{Appendix}

\section{Experimental Task}

The ATC simulation display showed four runways for aircraft, two running northsouth and two running east-west, one of each being short and the other long. In addition, 12 holding pattern positions at three altitude levels were positioned on the display. At the top of the screen was a queue stack with planes coming in every 6 seconds waiting to enter the holding pattern positions and to land (see Figure 1). In addition, information about the wind direction (north, south, east, and west), which was varied randomly during each task trial (twice a minute), was provided in the middle of the screen. The planes in this simulation were designated with simple call signs (the letter A, B, K or M and a number; e.g., B 613). In addition, the number of minutes of fuel remaining was displayed. A plane crashed 4 to 6 minutes after appearing on the display if it did not land on the appropriate runway (in real time).

Participants were instructed to follow three general rules and four specific rules in order to perform the ATC task successfully. The three general rules were: (1) only one plane may occupy a runway at any time, (2) plane landings must be initiated from one of the four holding pattern positions in Level 1, and (3) planes are allowed to cross only one level at time. When participants deviated from a rule (e.g., landing two planes simultaneously on one runway), they received a short error message "This move is not allowed" and a 10-point penalty. In addition to these general rules, and most important for manipulating the task change, we used two sets of four specific rules (see Table 1): Participants were requested to land planes according to one rule set in the pre-change phase (trials 1-10) and a different rule set in the post-change phase (11-20). 


\section{Footnotes}

${ }^{1}$ In discontinuous models, the transition and reacquisition change terms (TA, RA, and $\mathrm{RA}^{2}$ ) can either be coded relative to other change terms or absolutely, relative to 0 . In this study, we used absolute coding because it was the most conservative type of coding for our study design. In particular, absolute coding indicates whether there was an absolute drop in performance from the pre-change level and whether there was an absolute increase in performance in the post-change period.

${ }^{2}$ Controlling for age and general mental ability did not fundamentally change the pattern of findings. Tables on request. 